\title{
ANALISIS PELAYANAN HOME VISITE ORANG DENGAN GANGGUAN JIWA DI RSJ KALAWA ATEI PROVINSI KALIMANTAN TENGAH
}

\section{Analysis of Home Visite Services of People With Mental Disorders at the Kalawa Atei Mental Hospital, Central Kalimantan Province}

\section{M.Rustam Effendy \\ R.Biroum Bernardianto Putri Irianti Sintaman}

Universitas Muhammadiyah Palangkaraya, Palangka Raya, Central Kalimantan, Indonesia

email:

muhammadrustameffendy@gmail.com

Kata Kunci:

Analisis

Pelayanan Publik

Home Visite

Keywords:

Analysis

Public services

Home Visite

\begin{abstract}
Abstrak
Penelitian ini bertujuan untuk menganalisis pelayanan home visite orang dengan gangguan jiwa di RSJ Kalawa Atei Provinsi Kalimantan Tengah. Mengingat pelaksanaan program tersebut untuk para penderita orang dengan gangguann jiwa untuk mengakases pelayanan kesehatan yang penangananya berbeda dari pelayanan kesehatan lainnya.

Penelitian ini menggunakan pendekatan kualitatif yang bertujuan menggambarkan tentang kompleksitas dan kedinamisaan penanganan penderita orang dengan ganguan jiwa. Adapun data primer dalam penelitian ini bersumber dari berberapa informan, yakni Para Petugas Home Visite dari RSJ Kalawa Atei, Dinas Sosial dan Dinas Kesehatan Povinsi/Kabupaten,Puskesmas setempat, dan Keluarga Panderita Ganguan Jiwa. Sedangkan, Sumber Sekunder dalam penelitian ini antara lain Regulasi Pelaksanaan Home Visite, Profile Pelayanan Home Visite, Rasio Pasien Home Visite dan Dokumen terkait lainnya.

Hasil Penelitian menunjukkan kesimpulan penelitian bahwa pelaksanaan pelayanan home visite yang diselenggarakan oleh RSJ Kalawa Atei Provinsi Kalimantan Tengah bersama lintas sektor lainnya sudah berjalan cukup baik. Hal ini dilihat dari segi sarana dan prasarana yang telah disediakan dalam memberikan pelaynan home visite bagi para ODGJ sudah dipersiapkan dan diupayakan dengan maksimal. Pelayanan home visite sudah sesuai dengan SOP, kompetensi dan disiplin ilmu yang dimiliki masing-masing petugas pelayanan. Pelayanan home visite memberikan jaminan kepada setiap pasien dengan terjadwalnya secara khusus yang dilakukan petugas untuk datang ke daerah-daerah untuk memberikan pelayanan tersebut. Dalam hal ini, Pelayanan home visite dari segi empati yang dilakukan petugas pelayanan sudah cukup baik. Mengingat kegiatan home viste ditunjukan kepada pasien gangguan jiwa berat, yang tidak dapat mengakses RSJ Kalawa Atei dengan berbagai sebab, seperti ketidak mampuan finansial, tidak ada dukungan keluarga, ketidaktahuan keluarga, dan adanya pemasungan. Namun ada beberapa faktor-faktor penghambat dalam pelaksanaan Pelayanan Home Visite RSJ Kalawa Atei, yaitu: I)kelengkapan peralatan, 2)kondisi lapangan, 3)komunikasi.
\end{abstract}

\section{Abstract}

This study aims to analyze the home visite services of people with mental disorders in Kalawa Atei General Hospital in Central Kalimantan Province. Given the implementation of the program for people with mental disorders to access health services whose handling is different from other health services.

This study uses a qualitative approach that aims to describe the complexity and dynamics of handling people with mental disorders. The primary data in this study were sourced from several informants, namely Home Visite Officers from Kalawa Atei General Hospital, Social Service and Povinsi / Regency Health Service, local Puskesmas, and Family of Ganguan Mental Panderita. Meanwhile, Secondary Sources in this study include the Implementation of Home Visite Regulation, Home Visite Service Profile, Home Visite Patient Ratio and other related documents.

The results of the study show the conclusions of the study that the implementation of home visite services organized by the Central Kalimantan Atei Central Hospital along with other cross sectors has been running quite well. This is seen in terms of the facilities and infrastructure that have been provided in providing home visite services for ODGJs that have been prepared and are maximally sought. Home visite services are in accordance with SOPs, competencies and disciplines of each service officer. Home visite services provide guarantees to each patient with a special schedule by officers to come to the regions to provide these services. In this case, home visite services in terms of empathy by service personnel are good enough. Considering that home viste activities are shown to severely mentally ill patients, who cannot access Kalawa Atei General Hospital for various reasons, such as financial incapacity, no family support, family ignorance, and the existence of savings. However, there are several inhibiting factors in the implementation of the Home Visite Service at Atawa Kalawa Hospital, namely: I) equipment completeness, 2) field conditions, 3) communication. 


\section{PENDAHULUAN}

Pelayanan kesehatan menjadi salah satu kewajiban pemerintah untuk memenuhi kebutuhan mendasar masyarakat serta menjamin setiap orang hidup sejahtera lahir dan batin serta memperoleh pelayanan kesehatan dengan menyelenggarakan sesuai amanat undang-undang Dasar 1945. Sehingga pelayanan kesehatan menjadi tempat yang sangat dibutuhkan oleh semua kalangan masyarakat. Kesehatan jiwa merupakan masalah kesehatan yang tidak terpisah dari masalah kesehatan lainnya dan merupakan salah satu masalah yang akan menjadi beban tanggungan pemerintah.

Penderita gangguan jiwa tidak bisa disamakan dengan penderita gangguan fisik lainnya yang mampu secara mandiri datang ke fasilitas pelayanan kesehatan baik fasilitas kesehatan pemerintah maupun swasta. Penderita gangguan jiwa atau orang dengan gangguan jiwa (ODGJ) memiliki keterbatasan sehingga mereka membutuhkan bantuan orang lain untuk bisa mengakses pelayanan kesehatan. Pihak keluarga yang memiliki latar belakang ekonomi yang lemah ditambah letak geografis yang jauh dan sulit untuk dijangkau, serta ketidakpahaman akan penaganan dan perawatan gagguan jiwa akan menambah sulitnnya orang dengan gangguan jiwa (ODGJ) untuk memperoleh pertolongan pelayanan kesehatan.

Pelayanan Kesehatan yang menangani pengobatan orang dengan gangguan jiwa (ODGJ) sejak pertama dirawat yang secara berkesinambungan dilakukan oleh rumah sakit jiwa (RSJ). RSJ Kalawa Atei merupakan satu-satunya rumah sakit dengan kekhususan pelayanan kesehatan jiwa dengann tugas menyediakan pelayanan kesehatan jiwa yang paripurna di wilayah Provinsi Kalimantan Tengah. Sebelum adannya RSJ Kalawa Atei banyak orang dengan gangguan jiwa di wilayah Kalimantan tengah yang melakukan perawatan dipanti jiwa milik swasta bahkan di Rumah Sakit Jiwa di provinsi tetangga, Kalimantan Selatan.

Sejak tahun 2017, rumah sakit jiwa kalawa atei membuka aset seluas-luasnya kepada masyarakat Kalimantan Tengah agar dapat menikmati layanan kesehatan jiwa dengan mendatangi langsung ke rumahrumah penderita gangguan jiwa, terutama penderita dengan pemasungan. Pemasungan dilakukan oleh pihak keluarga karena keterbatasan dan besarnya stigma maupun berujung pada perlakukan salah termasuk penelantaran. Sehingga RSJ memberikan pelayanan home visit bagi para penderita gangguan jiwa.

Namun pelaksanaan pelayanan home visite untuk penanganan orang dengan gangguan jiwa baik dengan atau tanpa pemasungan masih menjadi masalah terutama banyaknnya para penderita dengan gangguan jiwa di Provinsi Kalimantan Tengah. Para pasien gangguan jiwa berat yang tidak dapat mengakses Rumah Sakit Jiwa Kalawa Atei dengan sebab ketidak mampuan finansial,tidak ada dukungan keluarga dan adanya pemasungan.

Kemudian, permasalahan home visit juga karena memerlukan keterlibatan lintas sektor dan 
masyarakat setempat dimana orang dengan gangguan jiwa bertempat tinggal yang terkadang sulit untuk berkomunikasi. Dari permasalahan tersebut, maka peneliti ingin lebih lanjut meneliti tentang "Analisis Pelayanan Home Visite Orang Dengan Gangguan Jiwa di RSJ Kalawa Atei Provinsi Kalimantan Tengah”.

\section{METODOLOGI}

Penelitian ini menggunakan pendekatan kualitatif karena fenomena yang diteliti sangat kompleks dan dinamis. Kemudian, alasan peneliti menggunakan metode penelitian kualitatif karena peneliti ingin mendeksripsikan data berupa informasi yang ditemukan dilapangan yang akan digunakan untuk menganlisis meringkas berbagai kondisi. Adapun penelitian ini berjenis deksriftif kualitatif yang bertujuan menggambarkan tentang kompleksitas dan kedinamisaan penanganan penderita orang dengan ganguan jiwa.

Data untuk suatu penelitian dapat dikumpulkan dari berbagai sumber. Sumber data dibedakan atas sumber data primer dan sumber data sekunder. Adapun data primer dalam penelitian ini bersumber dari berberapa informan, yakni Para Petugas Home Visite dari RSJ Kalawa Atei, Dinas Sosial dan Dinas Kesehatan Povinsi/Kabupaten,Puskesmas setempat, dan Keluarga Panderita Ganguan Jiwa. Sedangkan, Sumber Sekunder dalam penelitian ini antara lain Regulasi Pelaksanaan Home Visite, Profile Pelayanan Home Visite, Rasio Pasien Home Visite dan Dokumen terkait lainnya.

\section{HASIL DAN PEMBAHASAN}

Pelayanan Home Visite merupakan inovasi dari RSJ Kalawa Atei sebagai program yang tidak bersikap menunggu pasien namun berupa memberikan pelayanan langsung kepada pasien dan keluarga yang membutuhkan layanan. Pelayanan home visite yang diselenggarakan oleh RSJ Kalawa Atei dalam mendukung komitmen dari pemerintah menyediakan akses layanan kesehatan sesuai kebutuhan masyarakat dengan harapan ODGJ dapat hidup berdampingan dengan masyarakat tanpa stigma sehingga ODGJ mendapatkan dukungan dan pertolongan dari semua pihak.

Pelayanan home visite didukung dengan anggaran di RSJ Kalawa Atei selama 3 tahun berturutturut telah dianggarkan sebagaimana tabel berikut ini :

Tabel I

Anggaran RSJ Kalawa Atei untuk pelaksanaan inovasi Tahun 2018-2020

\begin{tabular}{|c|c|c|c|}
\hline Tahun & Total Anggaran & Anggaran Untuk Inovasi & Persentase \\
\hline 2018 & 31.259 .286 .269 & 306.000 .000 & 0,98 \\
\hline 2019 & 34.145 .344 .788 & 242.050 .000 & 0,71 \\
\hline 2020 & 33.005 .678 .500 & 146.000 .000 & 0,44 \\
\hline
\end{tabular}

Sumber : RSJ Kalawa Atei, 2020

Berdasarkan tabel I diatas menunjukan bahwa pelaksanaan pelayanan home visite didukung dengan adanya anggaran yang telah disediakan. Walaupun setiap tahunnya ada penurunan anggaran yang terlihat dari nominal dan presentase dari tahun 2018-2020.

Program pelayanan home visite juga didukung oleh stakeholder baik internal dan eksternal RSJ Kalawa 
Atei. Pelaksana kegiatan home visite ini dilakukan oleh petugas yang ada di RSJ Kalawa Atei terdiri dari Dokter Spesialis kedoteran jiwa, dokter umum, perawat, dan tenaga administrasi yang menjadi stakeholder internal. Sedangkan stakeholder eksternal adalah Dinas Kesehatan Provinsi Kalimantan Tengah, Dinas Sosial Provinsi Kalimantan Tengah, Dinas Sosial dan Dinas Kesehatan Kabupaten/Kota serta pasien dan keluarga. Pembagian peran baik Stake Holder Internal dan eksternal dapat dilihat pada tabel dibawah ini :

Tabel 2

Identifikasi Stakeholders Internal

\begin{tabular}{|c|c|c|}
\hline No & $\begin{array}{l}\text { Stakeholders } \\
\text { Internal }\end{array}$ & Peran \\
\hline I & Direktur & $\begin{array}{l}\text { Menyetujui, memberi } \\
\text { dukungan dan arahan }\end{array}$ \\
\hline 2 & $\begin{array}{l}\text { Kepala Bidang } \\
\text { Pelayanan Medis }\end{array}$ & $\begin{array}{l}\text { Memberikan dukungan dan } \\
\text { arahan Memberikan solusi } \\
\text { terhadap masalah yang } \\
\text { ditemukan }\end{array}$ \\
\hline 3 & $\begin{array}{lr}\text { Kepala } & \text { Bagian } \\
\text { Administrasi } & \text { dan } \\
\text { Keuangan } & \end{array}$ & $\begin{array}{l}\text { Mendukung dalam } \\
\text { perencanaan dan } \\
\text { pengumpulan data untuk } \\
\text { monitoring dan evaluasi }\end{array}$ \\
\hline 4 & $\begin{array}{l}\text { Kepala Bidang } \\
\text { Penunjang Medis dan } \\
\text { Keperawatan }\end{array}$ & $\begin{array}{l}\text { Mendukung dalam } \\
\text { pelaksanaan, monitoring } \\
\text { dan evaluasi }\end{array}$ \\
\hline 5 & Team Work & $\begin{array}{l}\text { Menerima arahan } \\
\text { Melaksanakan kegiatan } \\
\text { Memelihara kerjasama } \\
\text { team } \\
\text { Menjaga komitmen tim }\end{array}$ \\
\hline
\end{tabular}

Tabel 3

Indetifikasi Stakrholders Eksternal

\begin{tabular}{|l|l|l|}
\hline No & \multicolumn{1}{|c|}{$\begin{array}{c}\text { Stakeholders } \\
\text { Internal }\end{array}$} & \multicolumn{1}{c|}{ Peran } \\
\hline I & $\begin{array}{l}\text { Dinas Kesehatan } \\
\text { Provinsi }\end{array}$ & $\begin{array}{l}\text { Koordinasi ke Dinkes } \\
\text { Kab/Kota }\end{array}$ \\
\hline
\end{tabular}

\begin{tabular}{|l|l|l|}
\hline 2 & Dinas Sosial provinsi & $\begin{array}{l}\text { Koordinasi ke Dinsos } \\
\text { Kab/Kota }\end{array}$ \\
\hline 3 & $\begin{array}{l}\text { Dinas Sosial } \\
\text { Kabupaten/Kota }\end{array}$ & $\begin{array}{l}\text { Koordiasi evaluasi } \\
\text { pasien }\end{array}$ \\
\hline 4 & $\begin{array}{l}\text { Dinas Kesehatan } \\
\text { Kab/Kota }\end{array}$ & $\begin{array}{l}\text { Koordinasi Pelayanan } \\
\text { kesehatan }\end{array}$ \\
\hline 5 & Pasien dan Keluarga & Sasaran kegiatan \\
\hline
\end{tabular}

Peneliti menggunakan pendapat Zeithaml dan Berry (Hutasoit,20I I:67) untuk mengetahui kualitas pelayanan home visite yang dirasakan secara nyata oleh penerima layanan, ada indikator ukuran kepuasan penerima layanan yang terletak pada lima variabel kualitas pelayanan menurut apa yang dikatakan penerima layanan. Kelima indikator tersebut, yaitu : Tangibles (Bukti Fisik), Reliability (Kehandalan), Responsiveness (Ketanggapan), Assurance (Jaminan) dan Emphaty (Empati).

I. Tangibles (Bukti Fisik)

Bukti fisik dari Kualitas pelayanan home visite berupa sarana dan prasarana, perlengkapan peralatan, kelengkapan seragam dan akomodasi. Tangibles merupakan bukti nyata dari kepedulian dan perhatian yang diberikan oleh penyedia jasa layanan tersebut, sehingga akan menimbulkan citra penyedia jasa terutama bagi yang baru menggunakan jasa tersebut.

Dari variabel tersebut, sarana dan prasarana yang telah disediakan dalam memberikan pelaynan home visite bagi para ODGJ sudah dipersiapkan dan diupayakan dengan maksimal. 


\section{Gambar I.}

Transportasi dan Peralatan Home Visite

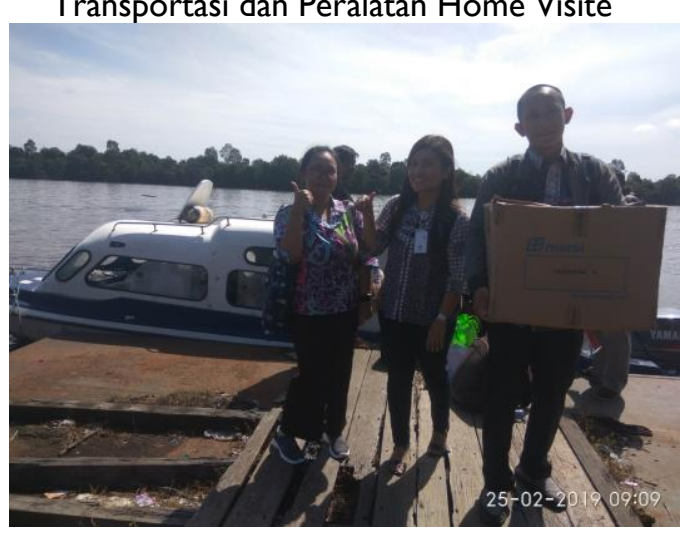

Sehingga dari pendapat tersebut dapat

disimpulkan bahwa sarana dan prasara yang disediakan

RSJ Kalawa Atei untuk para petugas yang melaksanakan pelayanan home visite sudah memadai dan cukup baik persiapannya. Akan tetapi, jarak dan lokasi yang dijangkau memang menjadi hambatan bagi para petugas. Mengingat lokasi atau daerah yang akan dituju adalah para pasien yang sulit mengakses kesehatan jiwa, sehingga para petugas menghadapi berbagai kondisi yang dirasakan oleh pasien.

Kemudian, selama ini tidak ada penyediaan seragam khsusus untuk para petugas pelayana home visite akan tetapi bisa ditangani dengan kesepakatan para tim/petugas yang berangkat untuk pelayanan home visite ke daerah.

Gambar 2.

Petugas Pelayanan Home Visite

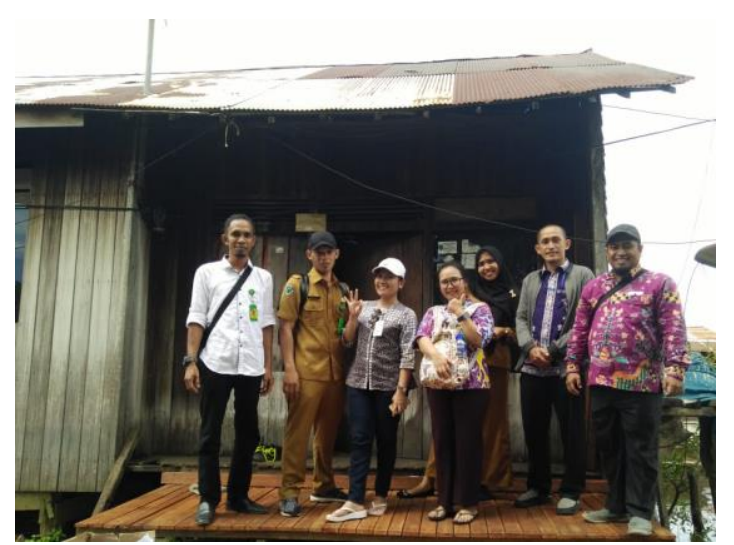

2. Reliability (Kehandalan)

Selain wujud pelayanan tersebut diatas, pelayanan publik memerlukan kehandalan sebagai kemampuan organisasi untuk melaksanakan pelayanan sesuai dengan apa yang telah dijanjikan secara benar, tepat waktu dan dapat terpercaya oleh yang menggunakan jasa layanan tersebut. Dalam hal ini RSJ Kalawa Atei Provinsi Kalimantan Tengah telah berupaya melaksanakan semua pelayanan home visite sesuai dengan prosedur yang ada.

Sebelum memberikan pelayanan home visite kepada para ODGJ, berbagai persiapan dilakukan oleh para petugas. Para petugas pelayanan home viste akan menjelaskan prosedur yang harus dilalui oleh para keluarga pasien ODGJ sesuai dengan mekanisme yang telah disiapkan. Sehingga dalam hal ini juga RSJ Kalawa Atei Provinsi Kalteng memberikan pelayanan yang sama bagi para ODGJ yang datang langsung ke RSJ Kalawa Atei ataupun pemberian layanan langsung kerumah pasien. Hal itu juga mencerminkan keadilan bagi siapapun ODGJ yang akan ditangani oleh para 
petugas pelayanan home visite. Mengingat hal ini dilaksanakan petugas pelayanan home viste sesuai dengan tujuan untuk meningkatkan kualitas hidup pendetita gangguan jiwa dengan ditandai tumbuhnya rasa percaya diri, mandiri, berinterasi sosial mampu memgembangkan bakat dan kemampuan.

Gambar 3.

Petugas Melakukan Briefing

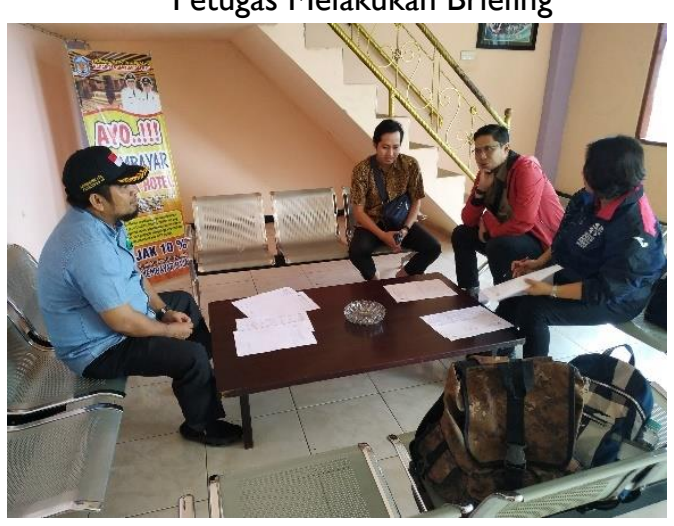

Dari ungkapan yang telah disampaikan menunjukkan bahwa para petugas selalu menjelaskan kepada keluarga pasien ODGJ terkait pemahaman kedatangan para petugas, sasaran, tujuan, dan pentingnya dilakukan home visite. Kemudian, pelayanan home visite juga bertujuan untuk menurunnya angka kekambuhan bagi para pasien sehingga perlu pelayanan yang sama dan adil bagi setiap pasien. Selama ini para petugas pelayanan home visite tidak memandang berbeda setiap pasien apalagi melihat dari strata sosial, latar belakang, pendidikan atau apapun. Mengingat pelayana home visite ini dilakukan untuk meningkatkan kualitas hidup para penderita ganguan jiwa.

3. Responsiveness (Ketanggapan)

$$
\text { Responsiveness atau daya tanggap }
$$
merupakan kemampuan para petugas yang dilakukan langsung untuk memberikan pelayanan dengan cepat dan tanggap. Sehingga, daya tanggap dapat menimbulkan persepsi terhadap kualitas jasa yang diberikan termasuk didalamnya jika terjadi kegagalan. Dimensi ini menekankan pada perhatian dan kecepatan karyawan serta tanggap dalam keinginan penerima layanan.

Dalam hal ini, para petugas cepat tanggap dalam melakukan pelayanan home viste walaupun masih terkendala dari sisi jarak, waktu dan adanya keluhan dari berbagai pihak. Mengingat penyelenggaraan kegiatan home visite ini mengacu kepada panduan home visite yang ditetapkan oleh RSJ Kalawa Atei dengan prosedur.

4. Assurance (Jaminan)

Assurance atau jaminan merupakan pengetahuan dan perilaku untuk membangun kepercayaan dan keyakinan pada diri penerima layanan atau dalam hal ini adalah ODGJ.

Pelayanan home visite memberikan jaminan kepada setiap pasien dengan terjadwalnya secara khusus yang dilakukan petugas untuk datang ke daerah-daerah untuk memberikan pelayanan tersebut. Dalam hal ini, kegiatan home visite dilakukan oleh petugas kesehatan RSJ Kalawa Atei 
secara periodik selama 2 hari efektif di satu kabupaten yang memiliki jumlah ODGJ terbanyak.

Kemudian mengenai jaminan kesembuhan pasien merupakan tujuan pelayanan home viste untuk menurunkan angka kekambuhan penderita gangguan jiwa sehingga kesembuhan total tidak dapat dijamin oleh para petugas home visite hanya saja melalui pelayanan home viste dapat memberikan kesehatan jiwa yang berangsur-angsur membaik

\section{Emphaty (Empati)}

Hal terpenting lain yang juga mencerminkan pelayanan publik yang baik adalah sikap empati dari setiap petugas pelayanan. Empati diartikan sebagai kemampuan para petugas pelayanan yang dilakukan langsung oleh petugas untuk memberikan perhatian kepada para pasien dan keluarga pasien termasuk juga kepekaan akan kebutuhan pengguna. Dalam hal ini tentunya para petugas pelayanan home visite di RSJ Kalawa Atei Provinsi Kalteng telah bersikap sopan dan ramah bagi para pemohon.

Pelayanan home visite dari segi empati yang dilakukan petugas pelayanan sudah cukup baik. Mengingat kegiatan home viste ditunjukan kepada pasien gangguan jiwa berat, yang tidak dapat mengakses RSJ Kalawa Atei dengan berbagai sebab, seperti ketidak mampuan finansial, tidak ada dukungan keluarga, ketidaktahuan keluarga, dan adanya pemasungan.
Kendala dalam hal ini yaitu pada komunikasi bahasa yang digunakan, karena ada beberapa bahasa daerah sulit untuk dipahami oleh para petugas home visite sehingga komunikasi terkadang sulit terjalin dengan baik antara petugas dengan pasien atau keluarga pasien. Namun hal ini bisa ditangani dengan adanya pihak lintas sektor yang terlibat seperti puskemas atau dinas terkait yang mendampingi pelayanan home visite.

\section{Faktor-Faktor Penghambat Peyelengaraan}

\section{Pelayanan Publik}

I. Kelengkapan Peralatan

Pelayanan home visite memerlukan usaha yang lebih untuk membawa kelengkapan peralatan yang akan menangani pasien di daerah. Mengingat home visite dilakukan untuk para pasien yang kesulitan mengakses untuk datang berobat di Rumah Sakit Jiwa Kalawa Atei Provinsi Kalimantan Tengah. Dalam hal ini para petugas telah mempersiapkan keberangkatan untuk logistic dan obat-obatan. Namun memang yang menjadi hambatan para petugas adalah ketidak lengkapan peralatan yang ada seperti tas obat yang perlu diadakan. Selain tas obat, para petugas juga tidak memiliki seragam khusus saat melakukan pelayanan home visite hanya dengan kesepakatan pemilihan baju dari tim yang bertugas saja.

\section{Kondisi Lapangan}


Mengingat pelaksanaan home visite adalah di daerah yang memiliki jumlah ODGJ terbanyak yang akan dikunjungi. Para petugas pelayanan home visite akan mendatangi kabupaten tersebut, dengan memerlukan trasnportasi yang memadai disebabkan oleh medan atau kondisi yang dilewati berbagai macam. Transportasi yang disiapkan untuk pelaksanan pelayanan home visite berupa transportasi darat dan transportasi air seperti mobil dan speed boat.

Kondisi lapangan yang dihadapi para petugas ini yang terkadang menjadi hambatan dalam pelaksanaan pelayanan home visite. Pelaksaanaan kegiatan yang diagendakan selama 4-5 hari dengan jangkauan jarak yang cukup jauh dengan berbagai medan yang dihadapi. Sehingga pelaksanaan yang efektif hanya berjalan 2 hari di satu daerah/kabupaten. Dalam hal inilah terkadang menghambat jadwal petugas untuk menangani semua pasien dan menunda pengobatan pasien yang belum tertangani untuk jadwal pada periode berikutnya.

3. Komunikasi

Komunikasi dalam pelaksanan pelayanan home viste menjadi faktor yang sangat penting. Hambatan yang terjadi dari sisi komunikasi adalah koordinasi kepada para lintas sektor yang terlibat dalam pelaksanaan pelayanan home visite. Selain itu, kendala bahasa juga menjadi aspek yang terkadang menjadi faktor penghambat pengobatan kepada pasien dan keluarga pasein. Mengingat sebelum menangani pasien, para petugas perlu menyampaikan maksud dan tujuan pelaksanaan pelayanan home visite kepada pihak keluarga.

Kendala pada komunikasi bahasa yang digunakan menjadi keterbatasan para petugas, karena ada perbedaan bahasa daerah dan beberapa bahasa daerah sulit untuk dipahami oleh para petugas home visite sehingga komunikasi terkadang sulit terjalin dengan baik antara petugas dengan pasien atau keluarga pasien. Walalupun dalam hal ini bisa ditangani dengan adanya pihak lintas sektor yang terlibat seperti puskemas atau dinas terkait yang mendampingi pelayanan home visite.

\section{KESIMPULAN}

Dari penelitian yang peneliti lakukan bahwa pelaksanaan pelayanan home visite yang diselenggarakan oleh RSJ Kalawa Atei Provinsi Kalimantan Tengah bersama lintas sektor lainnya sudah berjalan cukup baik. Hal ini dilihat dari segi sarana dan prasarana yang telah disediakan dalam memberikan pelaynan home visite bagi para ODGJ sudah dipersiapkan dan diupayakan dengan maksimal. Pelayanan home visite sudah sesuai dengan SOP, kompetensi dan disiplin ilmu yang dimiliki masingmasing petugas pelayanan. Pelayanan home visite memberikan jaminan kepada setiap pasien dengan terjadwalnya secara khusus yang dilakukan petugas untuk datang ke daerah-daerah untuk memberikan pelayanan tersebut. Dalam hal ini, Pelayanan home visite dari segi empati yang dilakukan petugas pelayanan 
sudah cukup baik. Mengingat kegiatan home viste ditunjukan kepada pasien gangguan jiwa berat, yang tidak dapat mengakses RSJ Kalawa Atei dengan berbagai sebab, seperti ketidak mampuan finansial, tidak ada dukungan keluarga, ketidaktahuan keluarga, dan adanya pemasungan.

Namun ada beberapa faktor-faktor penghambat dalam pelaksanaan Pelayanan Home Visite RSJ Kalawa Atei, yaitu :

I. Kelengkapan Peralatan

Faktor penghambat pertama adalah ketidak lengkapan peralatan yang ada seperti tas obat yang perlu diadakan. Selain tas obat, para petugas juga tidak memiliki seragam khusus saat melakukan pelayanan home visite.

2. Kondisi Lapangan

Kondisi lapangan yang dihadapi para petugas ini yang terkadang menjadi hambatan dalam pelaksanaan pelayanan home visite. Pelaksaanaan kegiatan yang diagendakan selama 4-5 hari dengan jangkauan jarak yang cukup jauh dengan berbagai medan yang dihadapi. Sehingga pelaksanaan yang efektif hanya berjalan 2 hari di satu daerah/kabupaten. Dalam hal inilah terkadang menghambat jadwal petugas untuk menangani semua pasien dan menunda pengobatan pasien yang belum tertangani untuk jadwal pada periode berikutnya.

3. Komunikasi
Kendala pada komunikasi bahasa yang digunakan menjadi keterbatasan para petugas, karena ada perbedaan bahasa daerah dan beberapa bahasa daerah sulit untuk dipahami oleh para petugas home visite sehingga komunikasi terkadang sulit terjalin dengan baik antara petugas dengan pasien atau keluarga pasien

\section{SARAN}

I. Perlunya pengadaan barang untuk tas obat dan seragam untuk para petugas pelayanan home visite di RSJ Kalawa Atei

2. Disarankan perlunya penggunaan aplikasi internet dalam pemantauan pasien ODGJ bekerjasama dengan lintas sektor.

3. Perlunya membangun komunikasi dengan keluarga pasien agar lebih memperhatikan kondisi pasien dan penguatan kerjasama lintas sektor untuk terus memantau pelaksanaan pelayanan home visite di daerah.

\section{REFERENSI}

Agustino, Leo. 20l4. Dasar-Dasar Kebijakan Publik. Bandung: CV.Alfabeta.

Anggara, Sahya. 2012. Ilmu Administrasi Negara. Bandung : CV.Pustaka Setia.

Hardiansyah. 20II. Kualitas Pelayanan Publik. Yogyakarta: Gave Media.

Kasmir.2006. Etika Costumer Servvice. Jakarta: PT. Raja Grafindo Persada

Mahmudi. 20I0. Manajemen Kinerja Sektor Publik, Edisi. kedua. Sekolah Tinggi Ilmu Manajemen YKPN. Yogyakarta. 
Moenir, H. A. S. 2002. Manajemen Pelayanan Umum Di Indonesia. Jakarta: Bumi Aksara.

Pasolong, Harbani. 2013. Kepemimpinan Birokrasi. Bandung : Cv.alfabeta.

Sedarmayanti. 2010. Reformasi Administrasi Publik, Reformasi Birokrasi, dan Kepemimpinan Masa Depan (Mewujudkan Pelayanan Prima dan Kepemerintahan yang Baik). Bandung: PT Refika Aditama.

Sinambela, Lijan Poltak. 20I0. Reformasi Pelayanan Publik. Jakarta: Bumi Aksara

Tangkilisan, Nogi Hessel. 2005. Manajemen Publik. PT. Gramedia Widiasarana Indonesia : Jakarta.

Tahir, Arifin. 20I4. Kebijakan Publik \& Transparansi Penyelenggaraan Pemerintah Daerah. Bandung : Alfabeta.

Tjiptono, F dan Chandra, G. 2005. Service, Quality And Satisfaction. Yogyakarta: Andi Offset.

Wahab, Solichin Abdul. 20I5. Analisis Kebijaksanaan Dari Formulasi ke Penyusunan Model-Model Implementasi Kebijakan Publik. Malang : Bumi Aksara.

\section{Peraturan Perundang-Undangan}

Keputusan Manteri Pendayagunaan Aparatur Negara (MENPAN) No. 36/2012 tentang Peningkatan Kualitas Pelayanan

Keputusan Menteri Pendayagunaan Aparatur Negara (MENPAN) Nomor 63 tahun 2004 tentang hakikat pelayanan publik

Peraturan Menteri Pendayagunaan Aparatur Negara Nomor 20 Tahun 2006. Tentang Pedoman Penyusunan Standar Pelayanan Publik. 